\title{
Trabalho e subjetividade. Nos rituais da iniciação, a constituição do ser professora
}

\author{
Roseli Cação Fontana*
}

\begin{abstract}
RESUMO: este texto procurou focalizar o movimento íntimo de constituição e singularização do "ser profissional" em uma jovem professora iniciante, ao longo de seu primeiro ano de trabalho no Ensino Fundamental. Construído numa relação de proximidade e de confiança, fundada na "comunidade de destinos" - a condição de mulheres-professoras - existente entre a pesquisadora e 0 sujeito da pesquisa, ele emerge da dinâmica interativa e discursiva tecida nos encontros entre ambas, nos quais a prática docente vivida no cotidiano da escola foi tematizada e analisada em suas condições sociais de produção e à luz da categoria de "drama", formulada por Politzer e incorporada por Vygotsky.
\end{abstract}

Palavras-chave: Subjetividade, singularização e formação de professores

Para Cristina, que compartilhando comigo a solidão do seu noviciado, possibilitou-me reviver meu tempo de iniciação.

Antecipo: não ando à cata de explicações. Muitas têm sido elaboradas a respeito de professores e professoras nas últimas décadas, contribuindo para nos inscrever na ordem social, pelo negativo, como um grupo profissional arrastado pela proletarização inexorável, destituído de identidade própria e de competência técnica, sempre a oscilar entre a resistência à mudança e a adesão superficial aos modismos em voga, desprovido de compromisso político e de capacidade de organização autônoma.

Isso tudo não é pouco, você, leitor, há de convir...

Se me preocupam os limites das explicações, exemplarmente ironizados por Cortázar - o que vamos fazer quando alguém explicar a

\footnotetext{
*Professora doutora da Faculdade de Educação, Unicamp. E-mail: roap@uol.com.br
} 
lata de lixo que recebe as muitas explicações? ${ }^{1}$-, sobressaltam-me mais os efeitos de sentido por elas produzidos sobre os indivíduos em constituição nas relações sociais em que se tece a vida.

Mudassem o foco, fosse possível, aqueles que nos explicam, e reparassem ao menos na trama miúda feita de sentidos peculiares, discreta e silente, que vamos tecendo no fluir obstinado (entediante ou efervescente) das relações e rituais cotidianos de trabalho, veriam eles as mesmas professoras, os mesmos professores?

Atentassem para a tensão constante que faz pulsar a rede móvel e multifacetada de relações de poder que perpassa as relações de trabalho que vivemos, e nas quais nos constituímos como profissionais de educação e indivíduos singulares, definiriam eles nossas relações com o trabalho apenas como relações de "alienação"?

A denúncia sem anúncio, bem o sabemos, tende a naturalizar-se, cristalizando-se como conceito prévio. E então, não mais se pensa no que se deixou de considerar, nem nas indagações possíveis, que não chegaram a ser formuladas, no momento mesmo em que se denunciou. "A gente não revê os que não valem a pena" (Rosa 1981, p. 109).

Por entre nossa dignidade profissional em escombros, tenho procurado me aproximar da banalidade, da insignificância e da impunidade de nosso cotidiano de trabalho, buscando, aí, compreender os processos singulares de constituição, em nós, do "ser profissional".

Como os atos, os gestos, os ritmos, as cadências e os comportamentos relativos à condição de professor imiscuem-se nos modos de agir, de pensar, de dizer, de se organizar, de regular impulsos e desejos, já consolidados e em elaboração em cada um de nós? Como vamos nos constituindo na rede de papéis e relações hierárquicas definidas pela organização do trabalho em que essa profissão se insere?

E também o inverso: como nossos modos de agir, pensar, dizer, nos organizar, regular impulsos e desejos, já consolidados e em elaboração imiscuem-se nos atos, gestos, ritmos, nas cadências e nos comportamentos vividos na rede de papéis e relações hierárquicas definidas pela condição de professor?

Como esse "ser profissional" vai se configurando, de modos singulares e diferenciados, no nosso afrontamento com as tarefas que caracterizam o ser professor, compondo possibilidades que, mesmo contraditórias, na vida não se excluem?

Nessa empreitada, o "drama" tem sido uma categoria de análise privilegiada. Entendido por Politzer (1977) e Vygotsky (1986) como a dinâmica 
contraditória em que a personalidade vai se produzindo nos eventos de nossa experiência, o drama remete ao constante choque de significados e de valores derivado do fato de vivermos, simultaneamente, lugares e papéis sociais diversos e distintos.

Não somos apenas professores, mas um feixe de muitas condições e papéis sociais, memória de sentidos diversos. Nós, professoras, somos muIheres numa sociedade ainda patriarcal. Somos mães, mas também filhas, netas e irmãs e ainda esposas ou "tias", "rainhas do lar", companheiras. Somos brancas, não-brancas, quase brancas, embranquecidas numa sociedade vincada pelo racismo. Aprendemos cantando que somos pobres ou ricas, de "ma-ré-de-si", numa sociedade dilacerada pelas desigualdades, em que nossa condição de assalariadas, ainda que nos agregue a muitos outros trabalhadores, é vivida, mesmo entre nós, de modo desigual, implicando grandes diferenças: moramos diferente, vestimos diferente, estudamos em escolas diferentes, ensinamos em condições diferentes a crianças também diferentes.

Nesse jogo, somos muitas a um só tempo. E essas muitas se multiplicam, já que sendo o que somos, somos também a negação do que não somos e, nesse sentido, o que não somos também nos constitui, está em nós. Ser e também não ser: aí radica e é produzida a singularidade.

Quando dizemos sim, quem, dessas muitas que somos, o diz? Quem em nós silencia, quem em nós defende este ou aquele princípio, quem em nós acata, quem recusa?

Singularidade e significação, essas são as características fundamentais do drama, segundo Politzer. Seus personagens são homens e mulheres singulares - pessoas $^{2}$ em constituição - que, em suas relações com os acontecimentos no interior dos quais se desenrola a vida, agem desta ou daquela maneira. Não somos processos psicológicos como percepção, memória, vontade, inteligência, representação, nem processos sociais como exploração, dominação, alienação. Somos pessoas nas quais nos reconhecemos e em quem foram e vão se constituindo e desenvolvendo funções psicológicas complexas, na dinâmica das relações sociais de poder em que se tecem os acontecimentos reais que vivemos. Acontecimentos que também são singulares no espaço e no tempo, e concebíveis apenas quando relacionados com indivíduos considerados na sua unidade singular (Politzer 1977, pp. 107/126).

Singularidade e significação não se oferecem como comportamentos à observação direta. Antes, inscrevem-se nos gestos e nas posturas dos indivíduos, deixando marcas em seus corpos. Entremeiam-se a suas palavras e a seus silêncios, deixam indícios em seus dizeres. Marcas e indícios significam e, mais do que explicação, requerem compreensão. 
A compreensão, diz Bakhtin (1986), "não pode manifestar-se senão através de um material semiótico" (p. 30), na medida em que "é uma forma de diálogo" (p. 132). Compreender é orientar-se em relação ao significado do acontecimento vivido, contrapondo a ele sentidos e significados já elaborados em nossas experiências. Em outras palavras, "a compreensão é uma resposta a um signo por meio de signos" (p. 34).

São os signos, socialmente produzidos e compartilhados, que tornam possível ao homem relacionar-se com o outro e consigo mesmo, aponta-nos Vygotsky. E aqui, os dois autores - Vygotsky e Bakhtin - aproximam-se: "o que faz da atividade psíquica uma atividade psíquica é sua significação" (Bakhtin 1986, p. 49).

Embora a atividade mental não seja visível nem possa ser diretamente percebida, ela é exprimível para o outro e para o próprio indivíduo, e igualmente elaborada e compreensível por meio de signos, nas relações intersubjetivas. "Fora de sua objetivação, de sua realização num material determinado (o gesto, a palavra, o grito), a consciência é uma ficção", ressalta Bakhtin (1986, p. 117). "O pensamento nasce através das palavras, (elas são) o microcosmo da consciência humana", declara Vygotsky (1987, p. 132).

Para nos acercarmos das relações interpessoais de indivíduos que vão se constituindo em condições sociais específicas e compreendê-las, mostram-se insuficientes as observações e análises objetivas que excluem as situações pontuais, efêmeras e contraditórias de dor e alegria, de serenidade e enfrentamento, de assentimento e de desobediência, ou os sentimentos de emoção, de angústia, de raiva, que são experimentados pelos sujeitos envolvidos em nossas indagações. Ao excluí-los, essas análises perdem de vista tanto "as pessoas", cujos comportamentos se deseja entender, quanto a dinâmica em que esses comportamentos nelas se constituíram e continuam se constituindo.

"(...) Sem a pessoa, não se pode entender o comportamento da pessoa", ensinou-me Vygotsky (1986, p. 51), pois é ela quem, na singularidade de sua história, nos possibilita o acesso às condições sociais de produção dos sentidos que já a constituem e dos que nela estão em elaboração, reafirmando ou redimensionando aqueles.

Além disso, ensinou-me o mesmo Vygotsky que "estudar alguma coisa historicamente é estudá-la no seu processo de mudança" (1984, p. 74). Mais do que apreender o sentido produzido, interessa o movimento em que ele vai sendo produzido, reproduzido e transformado; o movimento que sustenta e desloca a configuração apreendida e a regula; "(..) uma construção real do próprio processo. Este é um princípio básico" (1986, p. 33). 
Ao formular esse princípio, Vygotsky explicita os limites da observação na apreensão da dinâmica dos processos de desenvolvimento e de produção de sentidos, alertando que para apreender o movimento é necessário não só pesquisar dentro dele como provocá-lo. A intervenção experimental entendida como uma atuação sobre as relações em curso no contexto em estudo, jogando com suas condições sociais de produção, segundo ele, pode "provocar, criar artificialmente um processo de desenvolvimento psicológico" (1984, p. 74), fornecendo-nos indicadores da emergência e da internalização de modos de ação e de elaboração nos sujeitos envolvidos na pesquisa. Esses indicadores aparecem nos percursos, recursos e estratégias compartilhados por nós com eles e entre eles, no decorrer das atividades em que nos encontramos envolvidos.

Como realizar tal projeto? Como adentrar relações em que a própria condição humana vai se produzindo, na articulação e na contraposição de papéis e lugares sociais em jogo? Como participar de relações de poder, investidas de necessidades e interesses distintos, nas quais são produzidos signos e significados que constituem os indivíduos?

A idéia de participação costuma suscitar restrições apressadas e interpretações aligeiradas, como destaca Ecléa Bosi em seu belo trabalho sobre a memória.

Não basta a simpatia (sentimento fácil) pelo objeto de pesquisa, é preciso que nasça uma compreensão sedimentada no trabalho comum, na convivência, nas condições de vida muito semelhantes. (...) é preciso que se forme uma comunidade de destino para que se alcance uma compreensão plena de uma dada condição humana. Comunidade de destino já exclui, pela sua própria enunciação, as visitas ocasionais ou estágios temporários no locus da pesquisa. Significa sofrer de maneira irreversível (...) o destino dos sujeitos (estudados). (1987, p. 2; grifos da autora)

Nos episódios que se seguem, e que o convido a partilhar comigo, leitor, a comunidade de destino entre mim e a professora que os vivenciou edificou-se tanto sobre nossa condição profissional - éramos, então, e somos, ainda, professoras - quanto pela intersecção que se produziu entre nossas vidas: eu fui sua professora na universidade e as relações que construímos como professora e aluna possibilitaram que, reencontrando-nos dois anos depois, compartilhássemos as dificuldades e ansiedades de seu noviciado profissional e que, refletindo sobre ele, refletíssemos sobre nosso "ser professora" em constituição, dizendo-nos e sendo ditas, significando e ressignificando a nós próprias. 


\section{Os segredos selados na vivência do fazer-se professora}

\section{Verão}

Lá estava ela, lá estavam todos eles iniciando mais um ano de trabalho. Também ali estava eu a convite da coordenação pedagógica da escola, para falar aos professores. Era fevereiro, período de planejamento.

Aproximou-se. Os olhos grandes e expressivos brilhavam. O sorriso fácil iluminava-a. "Eu não vejo a hora de começar, de estar com as crianças. Sinto um pouco de medo, é claro, mas acho que vai ser tão bom!"

Acabara de se formar. Embora tivesse trabalhado como professora num curso supletivo, mantido por uma empresa, quando ainda na universidade, vivia, agora, sua primeira experiência como professora de uma terceira série da escola fundamental.

Seu entusiasmo evocou-me os tempos de iniciação, repleta de "boas intenções", "olhar crítico" e quase nenhum saber fazer. Um noviciado sofrido e solitário dentro da escola. Entre meus pares imediatos não encontrei a disponibilidade para o trabalho ombro a ombro, mediador da apropriação lenta das práticas, dos rituais, de sentimentos e de disposições emocionais que regulam nossa conduta como profissionais da educação. Experimenteios com meus alunos e em relações de trabalho vividas fora da escola.

Agora era ela a se experimentar nesse aprendizado no fazer.

No começo de março voltamos a nos ver. Eu havia levado meus fiIhos à escola. No pátio, ela recebia sua classe. Aproximou-se. Os olhos grandes e expressivos refletiam tristeza. Um sorriso tímido escasseava ...

- Não estou gostando da professora que eu estou sendo.

- Por quê? O que está acontecendo?

- A coordenadora tem reclamado que eu não tenho controle da classe. As crianças falam muito, brincam, riem, fazem barulho ao saírem de sala. Ela até me sugeriu que voltasse à universidade para fazer alguma disciplina da área de didática ou metodologia. Estou me sentindo uma incompetente. Comecei a ser chata, muito chata com as crianças. Tenho escrito muita coisa na lousa, tenho exigido silêncio. Até sermão eu tenho passado! Eu não gosto disso! Eu não acredito que essa seja uma boa forma para trabalhar com elas, para estar com elas, todos os dias, durante quatro horas. Como vai ficar a nossa relação? Eu queria muito conversar com você! 
Agendamos um horário. A história se repetia, pensei comigo mesma. Que a jovem professora não soubesse muitos dos segredos do trabalho docente, não me parecia novidade alguma. Ninguém nasce sabendo, diz o sábio e velho ditado popular. E também: é fazendo que se aprende...

A professora não está pronta em nós, quando começamos a trabaIhar. Pensando bem, não está pronta nunca, por mais estáveis, duráveis e semelhantes que pareçam ser nossas características como profissionais. $\mathrm{Na}$ nossa mesmice, pequenas novidades vêm à luz, produtos de sobressaltos e de acasos imponderáveis. Às vezes os seguimos delirantes. Outras, esforçamo-nos, também delirantes, por ignorá-los.

No entanto, o bom senso dos ditados populares parece não ter lugar na escola. Embora ela seja uma instituição social destinada ao ensino, não encontramos dentro dela quem nos ensine no próprio trabalho.

Quem, na escola, acompanha as buscas das professoras? Quem escuta o relato de suas dúvidas e a tomada de consciência de seu não-saber, assumindo a continuidade do seu processo de formação pelo/no trabalho? Quem faz com elas a análise do seu fazer na sala de aula, mediando seu desenvolvimento profissional emergente, procurando fazê-lo avançar e consolidar-se?

Contraditório? Nem tanto. As escolas nasceram em oposição ao trabalho, como evidencia a própria origem da palavra, schole - ócio. Como instituição, a escola ocupa um lugar específico na divisão social do trabalho: cabe-Ihe administrar um modo de circulação (utilizando-se de textos falados ou escritos) e de estabilização de algumas formas de interpretação do processo de produção do conhecimento, sobre outras. A realização dessa tarefa tanto medeia, quanto se faz pela mediação de uma outra - a normalização do comportamento da criança (do jovem ou do adulto) tendo em vista as exigências inscritas nesse modo de circulação do conhecimento.

Enquanto no aprendizado artesanal o mestre de ofício capacitava-se pelo trabalho e ensinava seus aprendizes no trabalho, olhando primeiro e produzindo em seguida, aprendendo a um só tempo os segredos de seu fazer e os comportamentos necessários a seu trabalho, na nossa escola busca-se disciplinar, conformar os impulsos, os desejos, as vontades do corpo, tendo em vista determinados modos de operar genéricos - atenção, prontidão, rapidez - que virão a ser necessários para um processo de trabalho e de produção de conhecimento que não se materializa na escola. Nessa mesma direção, anula-se, no interior da escola, o presente, convertendo-o em eterna promessa de futuro (Snyders 1993) e dissocia-se, pela disciplina, "o poder do corpo" (Foucault 1977, p. 127). 
Nesse contexto, ao papel social de professor, e em especial às professoras da escola fundamental, compete muito mais a tarefa de ensinar garantir a repetição daquelas formas de interpretação especificamente escolares - e fiscalizar, controlar e ordenar a conduta de seus alunos, do que compartilhar com eles relações de conhecimento. Na maioria das vezes, a expectativa institucional, em relação ao exercício da docência pelas jovens professoras, centra-se no exercício do disciplinamento, já que, do conteúdo, os livros didáticos podem dar conta, como prescrevia Comenius em 1657:

Com efeito, assim como qualquer organista executa qualquer sinfonia, olhando para a partitura, a qual talvez ele não fosse capaz de compor, nem de executar de cor só com a voz ou com o órgão, assim também porque é que não há-de o professor ensinar na escola todas as coisas, se tudo aquilo que deverá ensinar e, bem assim, os modos como o há-de ensinar, o tem escrito como que em partituras? (1985, p. 457)

"Você não tem controle da classe". Isso ouviu a jovem professora, isso ouvimos muitas de nós. Que nos revelemos aptas a dar conta do ritual da sala de aula, calcado na manutenção da ordem pelo controle do tempo e do comportamento dos alunos, tem sido um critério constantemente utilizado por nossos superiores hierárquicos na avaliação de nossa competência profissional.

A preocupação em manter o controle da classe, o que nos é explicitamente cobrado, passa a controlar o nosso fazer na escola, neutralizando nossas inquietações perante os fins das relações de ensino em que estamos imersas e perante os modos de aprender e de ensinar nelas em jogo. Interessadas em dar conta do que se espera de nós, vamos nos tornando artesãs de nosso próprio enredamento. Isso pressentiu a professora:

Comecei a ser chata, muito chata com as crianças. Tenho escrito muita coisa na lousa, tenho exigido silêncio. Até sermão eu tenho passado! Eu não gosto disso! Eu não acredito que essa seja uma boa forma para trabalhar com elas, para estar com elas, todos os dias, durante quatro horas. Como vai ficar a nossa relação?

Jogo perverso que nos expropria do "ser profissional", na medida em que, reduzindo-nos a executantes das normas, vai cerceando as possibilidades de produção e de elaboração, em nós, dos saberes de nosso ofício, pela participação efetiva na sua organização (concepção e modo operatório). 
Resistindo à desqualificação de sua imagem como professora - "estou me sentindo uma incompetente!" - e ao esvaziamento do significado do trabalho docente - "não estou gostando da professora que eu estou sendo" -, a jovem professora buscou um espaço de interlocução fora da escola. Um espaço em que pudesse falar a alguém, para, falando, pensar-se em suas relações no trabalho, elaborando-as e elaborando em si a professora.

Ao encontrarmo-nos na data agendada, angustiada e ansiosa, perguntava-me: "O que eu faço?". Calma! O caminho que você tem seguido não é a única forma de trabalhar com um grupo de crianças, você mesma me disse isso, lembra-se?. Também o modo como a coordenadora está interpretando o que acontece na sua sala não é necessariamente "verdadeiro" ou único. Como você analisa as atitudes das crianças em sala? Você também acha que é bagunça?

Um pouco de bagunça acontece, porque acabo me demorando nas correções, outras vezes as atividades são desinteressantes. Eu percebo, também, que algumas atividades precisam ser explicadas mais de uma vez, alguns se desinteressam e começam a conversar. $\mathrm{Na}$ saída para o recreio, eles descem as escadas conversando em voz alta, rindo... Mas eu vejo que, em muitos momentos, a classe está conversando, parece agitada, mas está trabalhando. Nas discussões, os alunos gostam de participar. Na hora de resolver exercícios, eles levantam do lugar para ajudar um colega ou para pedir "dicas", mas estão trabalhando, estão aprendendo!

É incrível! Nos momentos em que a classe está tranqüila, ninguém aparece para ver. Basta a classe se agitar e, pronto, a coordenadora entra em sala, me olha, dirige-se às crianças comentando sobre 0 barulho que elas estão fazendo. Eu tenho vontade de chorar! Fico me sentindo super mal diante dela e, principalmente, diante dos alunos. Por outro lado, na hora que eu endureço, exijo silêncio, à custa de lousas cheias, também me sinto naufragar. Eu não gosto de ser assim... Eu não quero ser uma professora desse jeito! O que eu faço?!

Mais do que ouvir explicações ou sugestões, poder manifestar-se a respeito do próprio trabalho, reconhecendo-se nele, poder pensá-lo e pensar-se nele, era pelo que a jovem professora ansiava e foi isso que a interlocução the possibilitou. Procurando responder à minha pergunta, ela voltou-se para a dinâmica das relações vividas na sala de aula e, analisando as atitudes e reações das crianças, olhou para seu modo de participação dentro delas, identificando possibilidades de interpretação distintas daquelas apontadas pela coordenadora. 
Enquanto o olhar da coordenadora só apreendia "bagunça" em sua classe, a professora, admitindo sem defensivas que o ruído e a movimentação realmente aconteciam, atribuiu-Ihes dois sentidos diversos e aparentemente opostos - bagunça e trabalho.

O ruído era parte do trabalho nos momentos em que a aprendizagem, porque significativa, nascia das interlocuções, do partilhamento dos modos de fazer e pensar entre as crianças e entre elas e a professora. Era o ruído do fazer junto, do confrontar possibilidades de significação e de elaboração.

A bagunça decorria, segundo sua análise, do desinteresse provocado pelas atividades que ela mesma propunha às crianças, ou da lentidão com que conduzia o desenvolvimento das mesmas. Nesse caso, o ruído nascia da impossibilidade do fazer junto, da falta (ou perda) de sentido da atividade, condições que ela ainda não sabia como resgatar.

Vivendo a angústia, o temor e a revolta provocados pelo julgamento desqualificador de seu trabalho e de sua formação, expresso na leitura reducionista da coordenadora, a professora, em sua fala ao outro, resistia à anulação de seu saber fazer: "na hora que eu endureço, exijo silêncio, à custa de lousas cheias, também me sinto naufragar. Eu não gosto de ser assim... Eu não quero ser uma professora desse jeito!"

Uma clara concepção de ensino norteava seu trabalho e a análise que dele fazia, bem como a compreensão por ela alcançada de suas dificuldades e limites diante dele. Embora continuasse perguntando à sua interlocutora o que fazer, em seu esforço de análise para o outro, a professora, mesmo sem dar-se conta de que o fazia, esboçara respostas possíveis para sua própria indagação, ao acercar-se dos seus modos de participação na relação de ensino e das condições sociais de produção que a determinavam.

Se havia que redimensionar aspectos presentes nos seus modos de participação, havia também que não perder de vista o fato de que as relações de ensino não nasciam nem se esgotavam nos limites da sala de aula. Um ouvido, atento ao menor ruído, esquadrinhava, por trás das portas, seu fazer e o fazer dos alunos, julgava-os, avaliava-os e, materializando-se sala adentro, demonstrava a uma e outros como o trabalho pedagógico estava dividido e hierarquizado na escola: quem mandava ali, quem definia concepções e regras a serem cumpridas e quem as controlava de modo a serem seguidas sem desvios.

O aprendizado pelo trabalho, que se deu a ver na análise feita pela professora, na interlocução estabelecida com alguém de fora da escola, convertia-se em sombra - silêncio e silenciamento - dentro dela. A vigilância 
sobre a professora iniciante, tomando o lugar da interlocução, silenciava suas opções teórico-metodológicas, a explicitação e a discussão dos significados e sentidos diversos que ela elaborava sobre seu trabalho e as questões e dificuldades que enfrentava. A clandestinidade, imposta pela própria organização do trabalho, não só dificultava a elaboração dos sentidos historicamente produzidos da docência, obstaculizando seu processo de qualificação profissional, como repercutia nas relações com seus pares.

Com quem compartilhar as dificuldades encontradas dentro da escola, quando um sentimento de "fracasso profissional" vai se tornando público pelas interferências, pelos olhares e comentários da coordenadora pedagógica?

Vivenciadas no isolamento e na solidão, as frustrações e ansiedades decorrentes das dificuldades encontradas no cotidiano de trabalho aumentam, destaca Dejours (1992, cap. 3) em seu estudo sobre as relações entre organização do trabalho e psiquismo, resultando em sentimentos de despersonalização, de paralisia da imaginação e de regressão intelectual. 0 silenciamento produzido pela vigilância cerceia o desenvolvimento pessoal.

No entanto, adverte-nos Orlandi (1995, p. 134), o silenciado "tem uma materialidade histórica presente nos processos de significação, de forma que na reprodução já há não-reprodução, na interdição dos sentidos, já estão sentidos outros".

Ao mesmo tempo em que vivia, pelo silenciamento imposto, o sentimento de despersonalização, reprodutor da organização do trabalho, a jovem professora reconhecia e elaborava (também silenciosamente) o tipo de trabalho de apoio de que necessitava (não-reprodução). Na medida em que não o encontrava nos modos como a escola funciona, buscava-o fora da escola, num movimento individual de resistência, colocando sob desconfiança o serviço de coordenação pedagógica que Ihe era oferecido e respondendo a ele com o "seu" silêncio. Não aquele imposto pelo não-reconhecimento de seu aprendizado e de seu fazer, mas silêncio ativo e eloqüente de uma resistência incômoda: a jovem professora "não falava do lugar que se esperava que falasse" (Orlandi 1995, p. 59).

\section{Outono}

Resistindo...

Em abril, a professora voltou a me pedir ajuda. Queria organizar com as crianças, e a pedido destas, um pequeno livro com o material obtido num estudo do meio. Estudando a história de Campinas, haviam percorrido áre- 
as centrais e históricas da cidade e um dos subdistritos do município. Haviam fotografado os pontos que lhes pareceram interessantes e registrado dados e impressões. De posse desse material, os alunos sugeriram à professora a possibilidade do livro. Ela acatara a proposta com entusiasmo, mas não sabia como conduzi-la. Eram muitas as possibilidades e idéias, era grande a ansiedade das crianças. Por onde começar? Como fazer?

As perguntas agora eram outras. A professora visualizava caminhos com seus alunos, queria viabilizá-los, mas não sabia como. Esse aprendizado seria possível dentro da escola se ali houvesse espaço para a reflexão, de quem trabalha na sala de aula, sobre os modos de ensinar vivenciados e sonhados, e não apenas a implementação de programas e técnicas de ensino escolhidos e definidos sem a sua participação. Novamente ela resistia individualmente.

Pensamos juntas algumas formas de viabilizar a organização, tanto das crianças para o trabalho quanto do material disponível. Uma semana depois, começada a atividade, a professora voltou. Os olhos grandes e expressivos marejados: "A coordenadora está se opondo ao trabalho, disse que eu vou perder muito tempo e atrasar o conteúdo de Estudos Sociais".

Buscamos juntas as brechas. Toda trama as tem. Encontrá-las exige olhar apurado ao habitual, ao habituado, exige ressignificar sentidos postos. Analisamos a distribuição das atividades no horário semanal e identificamos alguns momentos de que ela poderia dispor para a atividade do livro: o período dedicado à produção de textos, à leitura de fruição e à ida à biblioteca. Trabalhar na organização do livro nesses momentos não feriria os objetivos dessas outras atividades. Eles estariam se realizando na/pela própria organização do livro, pois as crianças estariam lendo, escrevendo, buscando informações complementares para um projeto significativo e altamente motivador para elas.

Reanimada, a professora retomou a empreitada. Novas objeções da coordenação: "Eu sei que você e as crianças estão entusiasmadas, mas é preciso resolver isso logo. Não se pode perder tanto tempo. Além disso, as outras terceiras séries não estão fazendo esse mesmo tipo de trabalho...". A ordem unida: todas juntas, mesmo passo, mesmo ritmo, mesma cadência a ilusão de um mesmo e único fazer. Tempo controlado e coordenado. Ousadia rompê-los. Movimentos e ações vigiados.

Um prazo foi então estipulado, pela coordenadora, para a conclusão da atividade. Preocupada em acelerar a finalização do projeto, a professora assumiu a preparação final do texto: digitou, reproduziu as fotos, cuidou da arte-final. Contou com ajuda de amigos, do namorado, dos ir- 
mãos. Assumiu, igualmente, todos os gastos. Apesar da urdidura fechada, a brecha havia sido ocupada.

Na primeira entrevista bimestral, ao final do mês de abril, exausta e feliz, apresentou o resultado do trabalho coletivo aos pais e às crianças. Diante do entusiasmo produzido, a coordenadora acolheu, sorridente, os elogios dos pais à iniciativa, e acatou a idéia da professora de entregar um exemplar daquele trabalho para a biblioteca da escola. Uma entrega solene, com direito a jogral, discurso da diretora e matéria no jornal da escola.

Entusiasmadas, as crianças passaram a propor novos projetos. O espaço conquistado crescia, sobressaltando a professora que, assustada, se perguntava e me perguntava como daria conta de tudo aquilo.

Analisamos outros modos de organização das sínteses dos estudos realizados. Os textos produzidos pelos alunos poderiam ser manuscritos e desenhados, ou digitados pelas próprias crianças, que tendo vivido uma primeira experiência coletivamente, poderiam, com sua assessoria, caminhar autonomamente, assumindo a totalidade do trabalho. Como os novos projetos estavam nascendo vinculados aos temas que estavam sendo estudados em Estudos Sociais e Ciências, bastaria aproveitar os mesmos momentos utilizados no trabalho anterior e, até mesmo, usar parte do tempo das lições de casa na organização das novas produções.

De novo o entusiasmo e o desejo de viabilizar um trabalho significativo com as crianças. De novo o brilho nos olhos. De novo, também, as objeções. Agora, comunicadas à professora pelos alunos:

A coordenadora encontrou a gente hoje de manhã, aqui na escola, e deu a maior bronca. Ela perguntou se nós estávamos de novo escrevendo um livrinho. Ela falou assim, professora: "Vocês de novo com essa história de livrinhos? Vamos parar com isso e tratar de estudar. É para isso que vocês estão na escola!".

E também direta e explosivamente:

- Você não vai começar de novo com essa loucura, não é? O conteúdo está atrasado...

- Não! O conteúdo não está atrasado! As professoras da manhã estão apenas duas lições na minha frente! As três classes assistiram ao vídeo no mesmo dia! Desde a primeira vez, eu cuidei para que a turma não se atrasasse!

- De qualquer modo, é melhor você não dar trela. Seus alunos têm vindo de manhã para a escola, sem a minha autorização. 


\section{- Eles têm vindo fazer consultas na biblioteca!}

- A biblioteca fica superlotada pela manhã. São muitas turmas. Não se esqueça de que a escola é grande...

O confronto entre concepções de educação estava explicitado. O cerco, assim como os espaços conquistados, também cresce quando ousamos resistir e romper. O medo e as incertezas não assaltam apenas aquele que ousa, mas também aquele que se sente ameaçado pela ruptura e, então, não há atenuantes: "(...) o preço da vitória é a eterna vigilância" (Lacerda 1986, p. 94).

\section{Inverno}

Junho. Os olhos grandes e expressivos estavam opacos, circundados por olheiras escuras. O sorriso apagara. "Eu não estou bem. Não vejo a hora de que o semestre acabe. O médico disse que é um quadro de estresse. Olha as minhas mãos. Estão sempre assim, frias e trêmulas. Eu sinto um cansaço tão grande! Parece até que estou a carregar o mundo nos meus ombros" - murmurou com a voz embargada, enquanto as lágrimas rolavam face abaixo.

Dominação e resistência, mais do que visíveis são sentidas e ditas por aqueles que as vivenciam. Inscrevem marcas em seus corpos: mãos frias e trêmulas, cansaço... Deixam indícios em seus dizeres: "Parece até que estou a carregar o mundo nos meus ombros".

Em cinco meses de um sofrido e exaustivo rito de iniciação, em que dia após dia havia que demarcar, por entre as brechas das relações de poder, espaços de atuação e negociar a preservação de sua inclusão no processo de trabalho, a jovem professora sentia os ombros curvarem-se. Apesar da luta contra a anulação de sua vontade, de suas convicções e esperanças, de seus projetos e desejos, sentia-se capitular, invadida pela vontade de um outro. Bloqueada em sua relação com o trabalho por um modo de organização e de hierarquização da atividade docente que ignora os significados e sentidos possíveis de que esta se reveste para quem a desempenha, a professora adoecia...

"A invisibilidade da violência do poder da norma materializado em relações de trabalho e condições de trabalho se faz visível nas doenças ditas 'profissionais' ou 'ocupacionais', dizimando a vida do trabalhador, suas capacidades físicas, mentais e intelectuais" (Rosa 1992, pp. 41-50).

Marx, em seus manuscritos de 1884, chamava de alienação à tolerância pelos trabalhadores de uma organização do trabalho que vai contra seus 
desejos, suas necessidades e sua saúde, em vez de fazer triunfar sua própria vontade. Como se produz essa tolerância no trabalhador?

A própria organização do trabalho é sua condição de produção, e se impõe pelo esgotamento, assinala Dejours. A neutralização prévia da vida mental, por meio da ação específica da organização do trabalho sobre a personalidade, é uma condição para a exploração e a desapropriação do corpo. Nesse sentido, "a 'carga psíquica' do trabalho não seria apenas um efeito acessório do trabalho, mas resultaria, exatamente, de uma etapa primordial, da qual dependeria a submissão do corpo, etapa cujo sucesso seria assegurado pela própria organização do trabalho" (op. cit., 136).

Mas mesmo nessas condições, assinala Rosa, "o trabalhador (re)age contra a violência (in)visível no seu corpo, quando se enuncia no sofrimento da doença (...)" (1992, p. 41). Por meio da doença, seu corpo não se dobra à sujeição da norma que fabrica o seu modo de ser ou sua subjetividade pelas relações de trabalho que o penalizam. Ele fala de um lugar que não se espera - o do drama -, onde se atualiza seu conflito com o poder.

\section{Primavera?...}

Dia do professor. Surpresa entre flores, presentes e festas muitas, organizadas pelas crianças de sua turma, a professora confessou-me de passagem:

Nunca fez tanto sentido, como agora, o que você nos dizia a respeito da solidão da escola, quando, estagiárias, criticávamos implacáveis tudo aquilo que as professoras faziam em classe. É difícil, muito difícil ser professora. É difícil, muito difícil estar na escola, trabalhar na escola, decidir permanecer na escola, acreditar na escola, sem perder de vista nossas concepções e valores.

A organização do trabalho é elaborada ativa e contraditoriamente por nós e em nós, como dominação e resistência, submissão e rebeldia, disciplinamento (anulação) e preservação de nosso corpo e de nossa vontade.

As marcas e indícios desses embates podem passar despercebidos aos olhos dos que nos explicam, como escapam muitas vezes a nós próprios, empenhados que estamos em trabalhar e garantir nosso trabalho, em sermos aceitos, em acertar...

Considerar os processos por meio dos quais vamo-nos constituindo como profissionais singulares, na dinâmica das relações de trabalho e explicitar em nós, como grupo profissional e como indivíduos, as marcas da 
organização do trabalho que internalizamos e as modulações que ela sofre à medida que a vamos elaborando, sugere Dejours (1992, pp. 138-139), poderia nos ajudar a examinar o que tem se constituído como obstáculo, coletivamente experimentado, à nossa inclusão no processo do trabalho docente.

\title{
Notas
}

1. J. Cortázar, "Em algum lugar deve haver uma lixeira onde estão amontoadas todas as explicações./ Uma coisa inquieta neste exato panorama: o que possa acontecer no dia em que alguém consiga explicar também a lixeira". "Destino das explicações". Um tal de Lucas.

2. Vygotsky emprega o termo pessoa para referir-se à personalidade, à singularidade que vai se constituindo nos indivíduos na trama de suas relações sociais. Ele destaca: "Todas as funções superiores desenvolvem-se em filogenia, não de modo biológico, mas social; o significado mais primário - o mecanismo de tais funções - é uma cópia do social. Elas são relações internalizadas de uma ordem social, transferidas para a personalidade individual, a base da estrutura social da personalidade. Sua composição, gênese e função (modo de ação) - numa palavra, sua natureza - são sociais. Até mesmo quando transformadas na personalidade em processos psicológicos permanecem 'quasi-sociais'. O individual e o pessoal não estão opostos, mas são uma forma superior de sociabilidade

\section{Work and subjectiveness. In the initiation rituals, constitution of the being teacher}

\begin{abstract}
This text tried to focus on the movement of the constitution and uniqueness of the "being professional" of a young beginner teacher, during her first year of work in Fundamental Teaching. This movement was constructed in a relationship of proximity and trust, founded on the "community of destinies" - the condition of women-teachers - existing between the researcher and the subject of the research, and it emerges from the interactive and discursive dynamics that had been intertwined in the meetings between both of them, where teaching practice lived daily at school had been found a theme analyzed in its social conditions of production and through the category of "drama", formulated by Politzer and incorporated by Vygotsky.
\end{abstract}

\section{Referências bibliográficas}

BAKHTIN, M. Marxismo e filosofia da linguagem. São Paulo: Hucitec, 1986.

BOSI, E. Memória e sociedade: Lembranças de velhos. São Paulo: T.A. Queiróz e Edusp, 1987. 
COMENIUS, João Amós. A didáctica magna. Tratado da arte universal de ensinar tudo a todos. Lisboa: Fundação Calouste Gulbenkian, 1985. (Tradução de Joaquim Ferreira Gomes do texto latino da Didáctica magna contido no tomo I das Opera Didactica Ominia, ed. da Academia Scientiarum Bohemoslovenica, Praga.)

CORTÁZAR, J. "Destino das explicações". Um tal de Lucas. Mimeo. s.d.

DEJOURS, C. A loucura do trabalho. Estudos de psicopatologia do trabalho. São Paulo: Cortez e Oboré, 1992.

FOUCAULT, Michel. Vigiar e punir. Petrópolis: Vozes, 1977.

LACERDA, N.G. Manual de Tapeçaria. Rio de Janeiro: Philobiblion, 1986.

ORLANDI, Eni. As formas do silêncio no movimento dos sentidos. São Paulo: Ed. da Unicamp, 1995.

POLITZER, G. "Psicologia mitológica e psicologia científica". Os fundamentos da psicologia. Lisboa: Prelo, 1977, pp. 73-160.

ROSA, João Guimarães. "A benfazeja". Primeiras Estórias. Rio de Janeiro: Livraria José Olympio Ed., 1981.

ROSA, Maria Inês. "A produção da violência no corpo do trabalhador". Proposições nํำ [8]. Campinas, vol. 3, jul. de 1992, pp. 41-50.

SNYDERS, G. Alunos felizes. Rio de Janeiro: Paz e Terra, 1993.

VYGOTSKY, L.S. "The concrete human psychology - Um manuscrito inédito de Vygotsky". Psikhologiya nº 1. Moscou, 1986. (Tradução Enid A. Dobránszky).

"Problemas de método". A formação social da mente. São Paulo: Martins Fontes, 1984.

Pensamento e linguagem. São Paulo: Martins Fontes, 1987. 